\title{
Temporal evolution in caveolin 1 methylation levels during human esophageal carcinogenesis
}

\author{
Zhe Jin ${ }^{1,3,4,5^{*}+}$, Liang Wang ${ }^{1,4 \dagger}$, Ziyi Cao ${ }^{1+}$, Yulan Cheng ${ }^{2}$, Yan Gao ${ }^{6}$, Xianling Feng ${ }^{1}$, Si Chen ${ }^{1}$, Huimin Yu ${ }^{1}$, \\ Wenjing Wu' ${ }^{2}$, Zhenfu Zhao', Ming Dong ${ }^{1}$, Xiaojing Zhang ${ }^{1,4}$, Jie Liu' ${ }^{1}$ Xinmin Fan' ${ }^{1}$, Yuriko Mori ${ }^{2}$ \\ and Stephen J Meltzer ${ }^{2^{*}}$
}

\begin{abstract}
Background: Esophageal cancer ranks eighth among frequent cancers worldwide. Our aim was to investigate whether and at which neoplastic stage promoter hypermethylation of CAV1 is involved in human esophageal carcinogenesis.

Methods: Using real-time quantitative methylation-specific PCR (qMSP), we examined CAV1 promoter hypermethylation in 260 human esophageal tissue specimens. Real-time RT-PCR and qMSP were also performed on OE33 esophageal cancer cells before and after treatment with the demethylating agent, 5-aza-2'-deoxycytidine (5-Aza-dC).

Results: CAV1 hypermethylation showed highly discriminative ROC curve profiles, clearly distinguishing esophageal adenocarcinomas (EAC) and esophageal squamous cell carcinomas (ESCC) from normal esophagus (NE) (EAC vs. NE, $A U R O C=0.839$ and $p<0.0001$; ESCC vs. NE, AUROC $=0.920$ and $p<0.0001$ ). Both CAV1 methylation frequency and normalized methylation value (NMV) were significantly higher in Barrett's metaplasia (BE), low-grade and high-grade dysplasia occurring in BE (D), EAC, and ESCC than in NE (all $p<0.01$, respectively). Meanwhile, among 41 cases with matched NE and EAC or ESCC, CAV1 NMVs in EAC and ESCC (mean =0.273) were significantly higher than in corresponding NE (mean $=0.146 ; p<0.01$, Student's paired t-test). Treatment of OE33 EAC cells with 5-Aza-dC reduced CAV1 methylation and increased CAV1 mRNA expression.
\end{abstract}

Conclusions: CAV1 promoter hypermethylation is a frequent event in human esophageal carcinomas and is associated with early neoplastic progression in Barrett's esophagus.

Keywords: CAV1, Hypermethylation, EAC, ESCC

\section{Background}

Esophageal cancer ranks eighth among frequent cancers worldwide, with estimated over 480,000 new cases diagnosed and 400,000 deaths globally in 2008 [1]. There are two major histologic subtypes in esophageal cancer: esophageal adenocarcinoma (EAC), which is more prevalent in Western countries, with a rapid recent rate of increase in incidence; and esophageal squamous cell

\footnotetext{
* Correspondence: zhejin1995@yahoo.com; smeltzer@jhmi.edu ${ }^{\dagger}$ Equal contributors

'Department of Pathology, The Shenzhen University School of Medicine, 3688 Nanhai Ave, Rm 703, Nanshan, Shenzhen 518060, Guangdong, People's Republic of China

${ }^{2}$ Division of Gastroenterology, Department of Medicine, The Johns Hopkins University School of Medicine and Sidney Kimmel Comprehensive Cancer Center, Baltimore, MD, USA

Full list of author information is available at the end of the article
}

carcinoma (ESCC), which occurs at high frequencies in many developing countries, especially in Asia, and including China [2]. Since esophageal cancer exhibits highly aggressive behavior, with rapid progression to death $[3,4]$, it is essential to gain a better understanding of the molecular events underlying these tumors In order to make further inroads into survival, it is important to discover novel early detection biomarkers and targets for chemoprevention or therapy.

Caveolae, which are small (50-100 nanometer) invaginations of the plasma membrane in many vertebrate cell types, are vital subcellular structures that regulate endocytosis, vesicular traffic, and signal transduction [5]. Caveolin-1 (CAV1), a cytoplasmic 22-kDa scaffold protein, is an essential component of caveolae [6]. In recent years, several studies have reported downregulation of 
CAV1 protein levels in several malignancies, including ovarian, breast [7-10], prostate [11], oral squamous cell [12] and lung cancer [13]. Prade et al. also showed that the majority of EACs exhibit loss of CAV1 expression in tumor vs. matched normal esophageal epithelia [14]. These results suggest that reduced CAV1 expression may represent a general characteristic of tumors, and that $C A V 1$ may inhibit tumor formation. Aberrant methylation of promoter $\mathrm{CpG}$ islands upstream of tumor suppressor genes is now well-established as a major mechanism of gene inactivation in tumorigenesis [15], including in ESCC and EAC [16-23]. Several of these aberrantly methylated genes appear to represent useful prognostic markers, as they precede and predict the progression of $\mathrm{BE}$ to EAC. Aberrant promoter methylation of $C A V 1$ is associated with inactivation of its expression in breast and colorectal cancers [24-27]. Therefore, we hypothesized that CAV1 was inactivated via promoter hypermethylation in human esophageal cancers, and that hypermethylation of CAV1 constituted an early event in the genesis of EAC.

\section{Methods}

\section{Tissue samples}

In the current study, 67 normal esophagi (NE), 60 Barrett's metaplasias without dysplasia (BE), 19 low-grade (LGD) and 21 high-grade (HGD) dysplasias occurring in BE (D), 67 EACs, and 26 ESCCs were examined. Outcome data were derived from a comprehensive database maintained by the institution's cancer registry and from patients' medical records at the University of Maryland and Baltimore Veterans Affairs Medical Centers. All patients provided written informed consent under a protocol approved by the Institutional Review Boards at the University of Maryland and Baltimore Veterans Affairs Medical Centers, where all esophagogastroduodenoscopies were performed. Biopsies were taken using a standardized biopsy protocol, as previously described [17]. Research tissues were obtained from grossly apparent Barrett's epithelium or from mass lesions in patients manifesting these changes at endoscopic examination, and histology was confirmed using parallel aliquots obtained at endoscopy. All biopsy specimens were stored in liquid nitrogen before DNA/RNA extraction. Clinicopathologic characteristics are summarized in Table 1.

\section{Cell lines}

The EAC (OE33) cell line was obtained from collaborators at the University of Michigan (Dr. David Beer). These cells were cultured in $47.5 \%$ RPMI 1640, 47.5\% F-12 supplemented with $5 \%$ fetal bovine serum.

\section{DNA and RNA extraction}

Genomic DNA was extracted from biopsies and cultured cells using a DNeasy Tissue Kit (Qiagen, Valencia, CA).
Total RNA was isolated cultured cells using TRIzol reagent (Invitrogen, Carlsbad, CA). DNAs and RNAs were stored at $-80^{\circ} \mathrm{C}$ before analysis.

\section{Bisulfite treatment and real-time quantitative methylation-specific PCR}

DNA was treated with bisulfite to convert unmethylated cytosines to uracils prior to qMSP, as described previously [27]. Promoter methylation levels of $C A V 1$ were determined with the ABI 7900 Sequence Detection System (Applied Biosystems, Foster City, CA), using primers and probes as described previously [27]. A standard curve was generated using serial dilutions of CpGenome Universal Methylated DNA (CHEMICON, Temecula, CA). The normalized methylation value (NMV) was defined as follows: $\mathrm{NMV}=$ (CAV1-S/CAV1-FM)/(ACTB-S/ACTB-FM), where CAV1-S and $C A V 1-F M$ represent the methylation levels of $C A V 1$ in sample and universal methylated DNAs, respectively, while $A C T B-S$ and $A C T B-F M$ correspond to $\beta$-Actin in sample and universal methylated DNAs, respectively [21].

\section{Real-time quantitative RT-PCR}

To determine CAV1 mRNA levels, one-step real-time quantitative reverse-transcriptase polymerase chain reaction (RT-PCR) was performed using a Qiagen QuantiTect Probe RT-PCR Kit (Qiagen, Hilden, Germany) and the ABI 7900 Sequence Detection System (Applied Biosystems, Foster City, CA). Primers and probes were the same as previously reported [27]. $\beta$-Actin was used for normalization of data. A standard curve was generated using serial dilutions of qPCR Reference Total RNA (Clontech, Mountainview, CA). The normalized mRNA value (NRV) was calculated according to the following formula for relative expression of target mRNA: NRV $=(\operatorname{TarS} / \operatorname{Tar} C) /(A C T B-S / A C T B-C)$, where $\operatorname{Tar} S$ and $\operatorname{Tar} C$ represent levels of mRNA expression for the target gene in sample and control mRNAs, respectively, whereas $A C T B-S$ and $A C T B-C$ correspond to amplified $\beta$-Actin levels in sample and control mRNAs, respectively [21].

\section{5-Aza-dC treatment of esophageal cancer cell lines}

To determine whether $C A V 1$ inactivation was due to promoter hypermethylation in esophageal cancer, OE33 EAC cells were subjected to 5-Aza-dC (Sigma, St. Louis, MO) treatment as previously described [21]. Briefly, $1 \times$ $10^{5}$ cells $/ \mathrm{ml}$ were seeded onto a $100 \mathrm{~mm}$ dish and grown for $24 \mathrm{~h}$. Then, 1 ul of $5 \mathrm{mM} 5$-Aza-dC per ml of cells was added every 24 hours for 6 days. DNA and RNA were harvested on day 4.

\section{Data analysis and statistics}

Receiver-operator characteristic (ROC) curve analysis [28] was performed using NMVs for the 67 EAC, 26 ESCC and 67 NE by Analyse-it software (Version 1.71, Analyse- 
Table 1 Clinicopathologic characteristics and methylation status of Caveolin 1 in human esophageal tissues

\begin{tabular}{|c|c|c|c|c|c|c|c|c|}
\hline \multirow[b]{2}{*}{ Clinical characteristics } & \multirow{2}{*}{$\begin{array}{c}\text { Number } \\
\text { of samples }\end{array}$} & \multirow{2}{*}{$\begin{array}{c}\text { Age } \\
\text { (year) mean }\end{array}$} & \multicolumn{2}{|r|}{ NMV } & \multicolumn{4}{|c|}{ Methylation status (cutoff 0.2 ) } \\
\hline & & & Mean & $p$ & Frequency & UM & $M$ & $p$ \\
\hline \multicolumn{9}{|l|}{ Barrett's segment } \\
\hline Short-segment $(<3 \mathrm{~cm})$ & 14 & 62.3 & 0.327 & $>0.05^{\S}$ & $71.4 \%$ & 4 & 10 & $>0.05^{\ddagger}$ \\
\hline Long-segment ( $>=3 \mathrm{~cm}$ ) & 16 & 62.8 & 0.439 & & $81.3 \%$ & 3 & 13 & \\
\hline \multicolumn{9}{|l|}{ Histology } \\
\hline Normal esophagus & 67 & 64.4 & 0.134 & & $25.4 \%$ & 50 & 17 & \\
\hline Barrett's metaplasia & 60 & 63.7 & 0.374 & $<0.01^{* / \$}$ & $81.7 \%$ & 11 & 49 & ${ }^{*}<0.01^{\dagger}$ \\
\hline Dysplasia in Barrett's esophagus & 40 & 65.3 & 0.254 & $<0.01^{* / \S} /<0.01^{\$ / \S}$ & $60.0 \%$ & 16 & 24 & ${ }^{*}<0.01^{\dagger} /^{\$}<0.05^{\dagger}$ \\
\hline Low-grade dysplasia & 19 & 65.3 & 0.269 & $<0.01^{* / \$} /<0.05^{\$ / \$}$ & $57.9 \%$ & 8 & 11 & ${ }^{*}<0.01^{\dagger} /{ }^{\$}<0.05^{\dagger}$ \\
\hline High-grade dysplasia & 21 & 65.2 & 0.240 & $<0.01^{* / \S} /<0.01^{\$ / \S}$ & $61.9 \%$ & 8 & 13 & ${ }^{*}<0.01^{\dagger} /{ }^{\$}>0.05^{\dagger}$ \\
\hline EAC & 67 & 65.1 & 0.294 & $<0.01^{* / \$} /<0.01^{\$ / \S}$ & $65.7 \%$ & 23 & 44 & $\left.{ }^{*}<0.01^{\dagger}\right)^{\$}<0.05^{\dagger}$ \\
\hline Well differentiation & 10 & 66.2 & 0.344 & $>0.05^{\S \S}$ & $80.0 \%$ & 2 & 8 & $>0.05^{\ddagger}$ \\
\hline Moderate differentiation & 24 & 66.1 & 0.29 & & $58.3 \%$ & 10 & 14 & \\
\hline Poor differentiation & 22 & 65.5 & 0.297 & & $63.6 \%$ & 8 & 14 & \\
\hline Unknown & 11 & 61 & 0.252 & & $72.7 \%$ & 3 & 8 & \\
\hline ESCC & 26 & 62.5 & 0.326 & $<0.01^{* / \$}$ & $80.8 \%$ & 5 & 21 & ${ }^{*}<0.01^{\ddagger}$ \\
\hline Well differentiation & 3 & 61.7 & 0.307 & $>0.05^{\S \S}$ & $100.0 \%$ & 0 & 3 & $>0.05^{\ddagger}$ \\
\hline Moderate differentiation & 11 & 62.7 & 0.381 & & $90.9 \%$ & 1 & 10 & \\
\hline Poor differentiation & 5 & 64.2 & 0.256 & & $80.0 \%$ & 1 & 4 & \\
\hline Unknown & 7 & 61.1 & 0.299 & & $57.1 \%$ & 3 & 4 & \\
\hline \multicolumn{9}{|l|}{ Stage of EAC patients } \\
\hline । & 7 & 63 & 0.358 & $>0.05^{\S \S}$ & $71.4 \%$ & 2 & 5 & $>0.05^{\ddagger}$ \\
\hline$\|$ & 15 & 65.2 & 0.286 & & $73.3 \%$ & 4 & 11 & \\
\hline III & 25 & 64.6 & 0.284 & & $56.0 \%$ & 11 & 14 & \\
\hline IV & 7 & 66.3 & 0.242 & & $28.6 \%$ & 5 & 2 & \\
\hline \multicolumn{9}{|c|}{ Lymph node metastasis in EAC patients } \\
\hline Negative & 25 & 64.9 & 0.314 & $>0.05^{\S}$ & $64.0 \%$ & 9 & 16 & $>0.05^{\dagger}$ \\
\hline Positive & 25 & 64.6 & 0.276 & & $56.0 \%$ & 11 & 14 & \\
\hline \multicolumn{9}{|l|}{ Smoking status of EAC patients } \\
\hline Never & 6 & 58.5 & 0.325 & $>0.05^{\S \S}$ & $83.3 \%$ & 1 & 5 & $>0.05^{\ddagger}$ \\
\hline Former & 24 & 68.5 & 0.276 & & $62.5 \%$ & 9 & 15 & \\
\hline Current & 13 & 60.8 & 0.303 & & $53.8 \%$ & 6 & 7 & \\
\hline \multicolumn{9}{|c|}{ Alcohol consumption of EAC patients } \\
\hline Never & 16 & 65.3 & 0.285 & $>0.05^{\S \S}$ & $68.8 \%$ & 5 & 11 & $>0.05^{\ddagger}$ \\
\hline Former & 15 & 63 & 0.302 & & $66.7 \%$ & 5 & 10 & \\
\hline Current & 10 & 65.7 & 0.315 & & $60.0 \%$ & 4 & 6 & \\
\hline
\end{tabular}

EAC: esophageal adenocarcinoma; ESCC: esophageal squamous cell carcinoma; NMV: normalized methylation value; UM, unmethylated; M, methylated; ${ }^{\S}$ Student's $t$ test; ${ }^{*}$ Comparisons made to normal esophagus; ${ }^{*}$ Comparisons made to Barrett's metaplasia; ${ }^{\S \S} \mathrm{Kruskal}$-Wallis test; ${ }^{\dagger} \mathrm{Chi}$-square for independence test; ${ }^{\ddagger}$ Fisher's exact test.

it Software, Leeds, UK). Using this approach, the area under the ROC curve (AUROC) yielded optimal sensitivity and specificity to distinguish normal from malignant esophageal tissues, and corresponding NMV thresholds were calculated for $C A V 1$. The cutoff value determined from this ROC curve was applied to determine the frequency of CAV1 methylation in each tissue type included in the present study. For all other tests, Statistica (version 6.1; StatSoft, Inc., Tulsa, OK) was used. Differences with $\mathrm{p}<0.05$ were deemed significant. 


\section{Results and discussion}

\section{CAV1 promoter hypermethylation in different esophageal tissues}

Promoter hypermethylation of the CAV1 gene was analyzed in $67 \mathrm{NE}, 60 \mathrm{BE}, 40 \mathrm{D}$ (19 LGD and $21 \mathrm{HGD}$ ), 67 EAC and 26 ESCC samples. All assays in this study were performed in duplicate format, and data showed reproducible and concordant results. CAV1 promoter hypermethylation showed highly discriminative ROC curve profiles, which clearly distinguished both EAC $(\mathrm{p}<0.0001)$ and ESCC ( $\mathrm{p}<0.0001$ ) from NE. AUROC of EAC vs. NE and ESCC vs. NE were 0.839 and 0.920 , respectively. ROC curves with corresponding AUROCs for CAV1 of EAC vs. $\mathrm{NE}$ and ESCC $v s . \mathrm{NE}$ are displayed in Figure 1.

The cutoff NMV for CAV1 (0.2) was chosen from ROC curves to maximize sensitivity and specificity. Mean NMV and frequency of $C A V 1$ hypermethylation for each tissue type are shown in Table 1. The mean NMV of CAV1 was significantly higher in ESCC (0.326), EAC (0.294), D (0.254), HGD (0.240), LGD (0.269) and BE (0.374) than in NE $(0.134 ; \mathrm{p}<0.01$, Student's t-test). The frequency of CAV1 hypermethylation was increased in $\mathrm{BE}(81.7 \%), \mathrm{D}(60 \%)$, and EAC (65.7\%) vs. NE (25.4\%; $\mathrm{p}<0.01, \mathrm{p}<0.01$ and $\mathrm{p}<0.01$, respectively; Chi-square for independence test). CAV1 was hypermethylated in 21 (80.8\%) of 26 ESCCs. There were no significant differences between EAC and ESCC in mean CAV1 NMV (0.294 vs. $0.326 ; \mathrm{p}>0.05)$ or hypermethylation frequency $(65.7 \% v s$. $80.8 \%, \mathrm{p}>0.05)$. Among 41 cases with matched NE and $\mathrm{T}$ (EAC or ESCC), CAV1 NMVs in T (mean $=0.273$ ) were significantly higher than in corresponding $\mathrm{NE}$ (mean $=0.146 ; \mathrm{p}<0.01$, Student's paired t-test; Figure 2A and $\mathrm{B})$. Among 15 cases with corresponding NE, BE and
EAC, one (No.8) was methylated only in EAC, three (No.7, 13 and 17) were methylated only in BE, five (No.1, $6,9,14$ and 28) were methylated in both $\mathrm{BE}$ and EAC, and the remaining six were methylated in $\mathrm{NE}, \mathrm{BE}$ and EAC simultaneously (Figure 2C). In addition, both CAV1 mean NMV and hypermethylation frequency were significantly higher in $\mathrm{BE}(0.374,81.7 \%)$ than in $\mathrm{D}(0.254,60 \%)$ and $\operatorname{EAC}(0.294,65.7 \% ; \mathrm{p}<0.01$ and $\mathrm{p}<0.05$, respectively; Figure 3).

No significant associations were observed between CAV1 promoter hypermethylation and patient age, survival (data not shown), smoking or alcohol consumption status, $\mathrm{BE}$ segment length, tumor stage or lymph node metastasis, histologic tumor differentiation, or histologic type of esophageal carcinoma (Table 1).

\section{CAV1 methylation and mRNA levels in OE33 cells after 5-Aza-dC treatment}

OE33 cells were subjected to demethylation by 5-Aza$\mathrm{dC}$ treatment. On day 4 after 5 -Aza-dC treatment, the NMV of CAV1 was diminished, while CAV1 mRNA levels were increased (Figure 4).

$C A V 1$ has already been previously reported to have tumor suppressor activity via. inhibiting cell proliferation and/or metastesis in several human cancers [29-32]. CAV1 down-regulation has been reported in many types of cancer, including breast, lung, oral and esophagus $[9,10,12-14]$. These results suggest that low expression of CAV1 may represent a general characteristic or even a requirement of transformed cells in many kinds of carcinogenesis. Potential mechanisms underlying this suppression of expression include posttranscriptional and epigenetic changes, such as aberrant DNA methylation
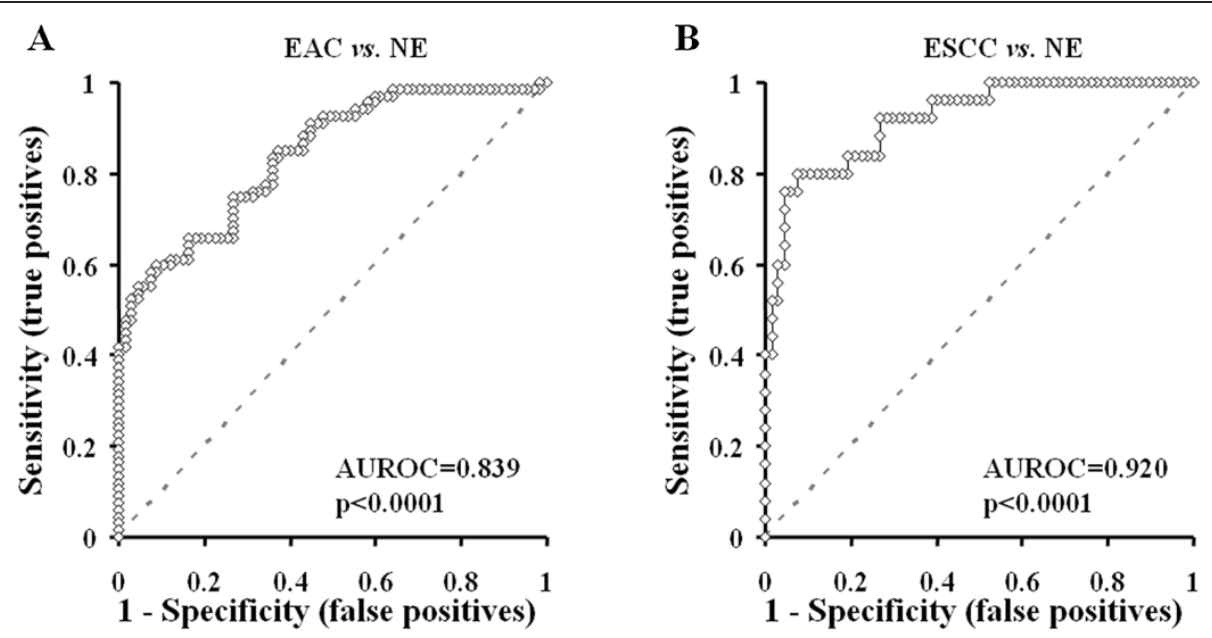

- - - No discrimination $\sim$ CAV1

Figure 1 Receiver-operator characteristic (ROC) curve analysis of normalized methylation value (NMV). ROC curve analysis of CAV1 NMVs of normal esophagus (NE) vs. esophageal adenocarcinoma (EAC) (A), and NE vs. esophageal squamous cell carcinoma (ESCC) (B). The area under the ROC curve (AUROC) conveys this biomarker's accuracy in distinguishing NE from EAC and from ESCC in terms of its sensitivity and specificity. 

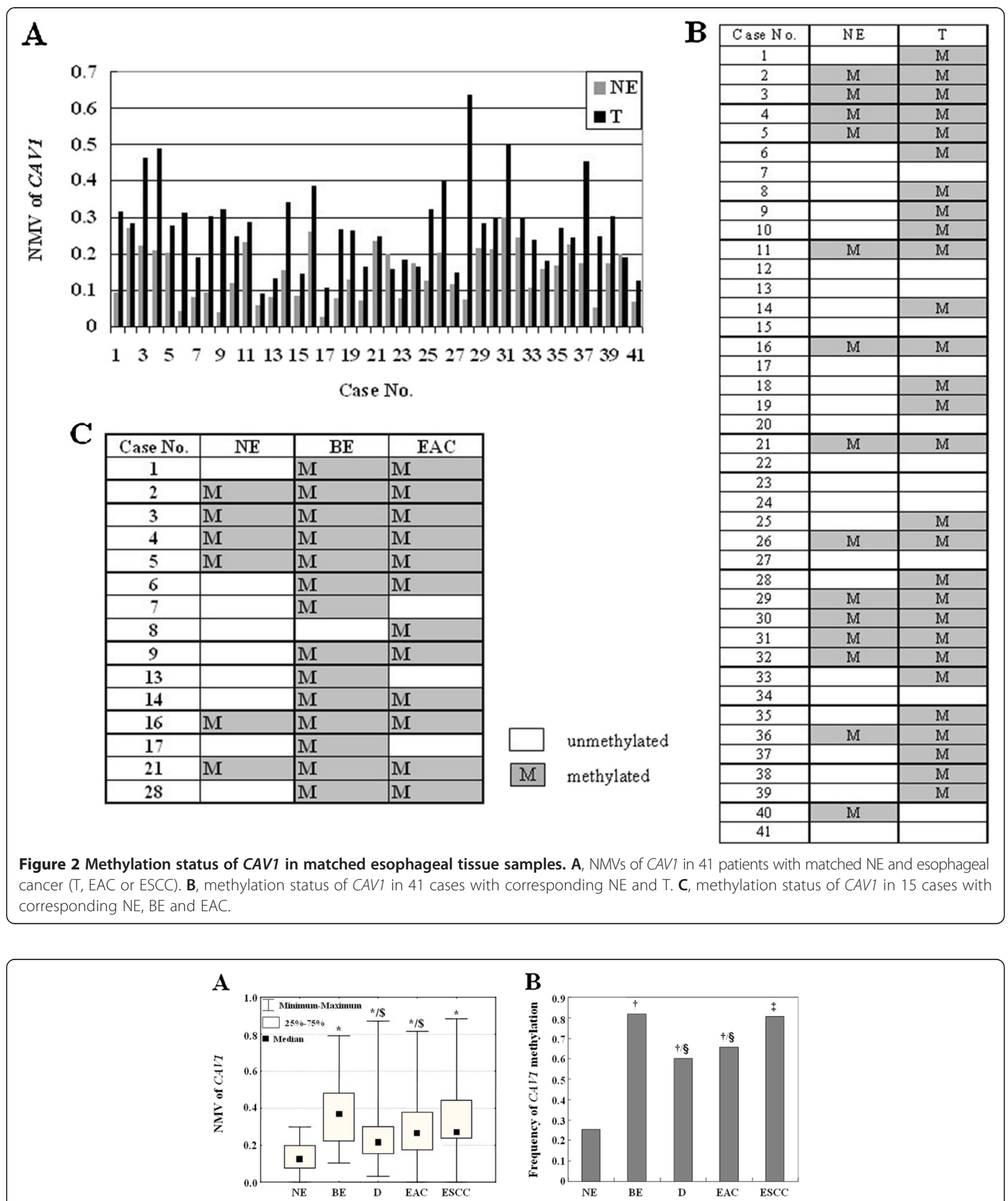

Figure 3 Methylation profiles of CAV1 in different esophageal tissue samples. A, The mean NMV of CAV1 was significantly higher in ESCC, $E A C, D$, and $B E$ than in $N E$, and in $B E$ than in $D$ and EAC. B. The frequency of CAV1 hypermethylation was significantly higher in $B E, D, E A C$ and ESCC than in NE, and in BE than in D and EAC. NE: normal esophagus; BE: Barrett's metaplasia; D: Dysplasia in BE; EAC: esophageal adenocarcinoma; ESCC: esophageal squamous cell carcinoma; *: Student's t test, $p<0.01$ (comparisons made to NE); \$: Student's t test, $p<0.01$ (comparisons made to BE); $t$ : Chi-square for independence test, $p<0.01$ (comparisons made to NE); ¥: Fisher's exact test, $p<0.01$ (comparisons made to NE); $\S$ : Chi-square for independence test, $\mathrm{p}<0.05$ (comparisons made to $\mathrm{BE}$ ). 


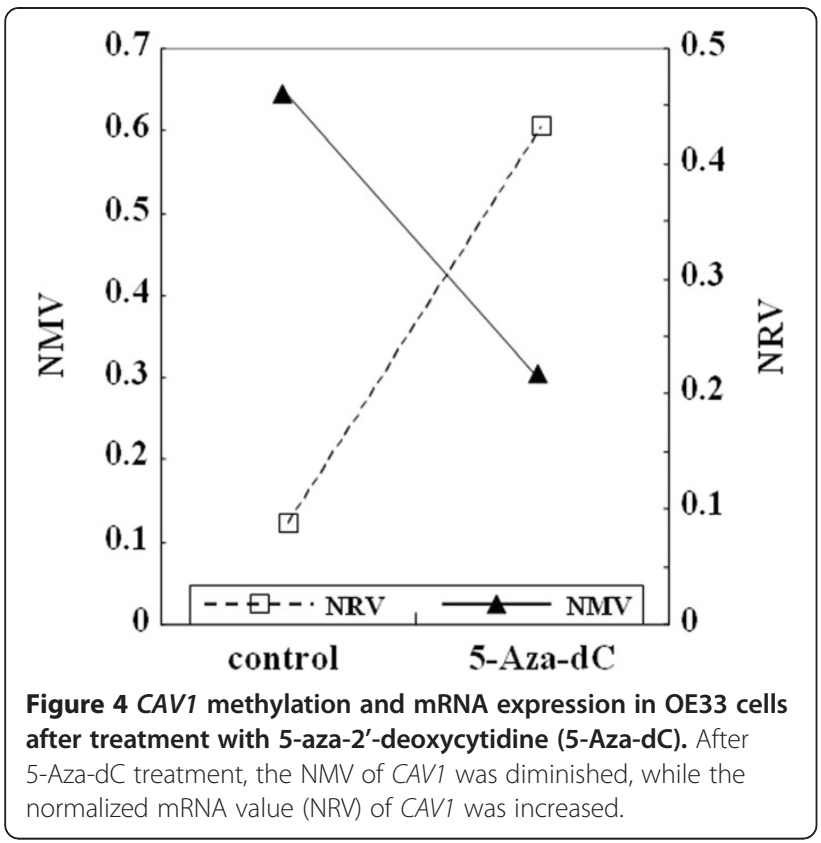

$[26,27,33]$. In the current study, we systematically investigated hypermethylation of the CAV1 gene promoter in primary human esophageal lesions of differing histological types and grades. Our results demonstrate that $C A V 1$ promoter hypermethylation occurs frequently in both human EAC and ESCC (Table 1). CAV1 NMVs in T were significantly higher than those in corresponding NE $(\mathrm{p}<0.01$, Student's paired $\mathrm{t}$-test) in 41 cases with corresponding NE and $\mathrm{T}$ (Figure 2). Moreover, hypermethylation of the CAV1 promoter was significantly more frequent in premalignant lesions, such as $\mathrm{BE}$ and $\mathrm{D}$, as well as in EAC, than in NE (Table 1). There was no significant association between $C A V 1$ promoter hypermethylation and histological subtype of esophageal carcinoma (EAC vs. ESCC). These results suggest that hypermethylation of CAV1 may represent an early epigenetic event in these subjects, that the frequency of this epigenetic event increases during esophageal carcinogenesis, and that this event is highly prevalent in human esophageal cancers.

Barrett's carcinogenesis is a multistep process comprising genetic and epigenetic alterations in tumor suppressor genes, cell cycle-regulatory genes, and genes essential for cell-cell adhesion [34,35]. Progressive accumulation of gene alterations is postulated to underly the transition of normal squamous epithelium to BE [36]. Many previous studies, focused on promoter hypermethylation of candidate genes for esophageal carcinomas, have shown staged growth in methylation frequency from nondysplastic esophageal squamous cell mucosa to BE and finally to EAC $[15,37,38]$. Interestingly, it has been suggested that $C A V 1$ acts as a tumor modulator in a tissue type- and stage-dependent manner by binding several different proteins involved in different signal transduction [6,39-42].
Recently, we reported a preponderance of hypomethylation over hypermethylation events during the epigenomic program of BE pre-progression by comparing global DNA methylation profiles of two groups of BE patients, termed 'progressors' and 'non-progressors' [16]. Although the frequency of $C A V 1$ hypermethylation in this study increased in parallel with esophageal carcinoma progression, the mean NMV and frequency of CAV1 hypermethylation were higher in $\mathrm{BE}$ than in $\mathrm{D}$ and $\mathrm{EAC}$, and these differences were significant by Student's t test (i.e., there was an inverse correlation between $C A V 1$ hypermethylation and Barrett's-associated esophageal neoplastic progression) (Figure 3). Taken together, these data suggested that the CAV1 promoter is relatively hypomethylated in $\mathrm{EAC}$ and $\mathrm{D} v s . \mathrm{BE}$, implying that, at least in part, this event represents an early part of the temporal program of Barrett's-associated esophageal neoplastic progression. Two previous studies demonstrated that expression of CAV1 was elevated in ESCC compared to corresponding normal tissues, and its elevation was associated with malignant progression and poor survival $[43,44]$. These inconsistent results may have been due to different analytic methods used, ethnic groups studied, and smaller sample sizes in the previous studies.

In accordance with previous findings $[11,45,46]$, we observed that methylation of CAV1 in EAC cell lines was associated with silenced or reduced expression of CAV1 mRNA. In this study, reversal of methylation and restoration of $C A V 1$ expression were induced in OE33 cells by 5 -Aza-dC treatment (Figure 4). Restoration of CAV1 mRNA expression due to 5-Aza-dC treatment is consistent with the interpretation that DNA hypermethylation silences the $C A V 1$ gene. Although 5-Aza-dC or its derivatives have shown potential as therapeutic anticancer drugs [47-49], relatively hypomethylation of CAV1 in $\mathrm{EAC}$ and $\mathrm{D}$ vs. $\mathrm{BE}$ in the current study, and together with previous data on the re-expression of CAV1 in advance cancerf, would make CAV1 not an ideal molecular target for anti-cancer therapy involving demethylation in EAC patients.

\section{Conclusions}

The current study indicates that hypermethylation of the $C A V 1$ promoter, leading to gene silencing, is a common event in human esophageal cancer and occurs early during Barrett's-associated EAC. These results provide a basis for further research on $C A V 1$ as a potential biomarker for the early diagnosis, classification, stratification and prognostication of esophageal cancers.

\section{Abbreviations}

5-Aza-dC: 5-aza-2'-deoxycytidine; BE: Barrett's esophagus; CAV1: Caveolin-1; EAC: Esophageal adenocarcinomas; ESCC: Esophageal squamous cell carcinomas; NE: Normal esophagus; NMV: Normalized methylation value; qMSP: Real-time quantitative methylation-specific PCR; ROC: Receiver-operator characteristic. 


\section{Competing interests}

The authors declare that they have no competing interests.

\section{Authors' contributions}

ZJ and SJM designed the study. ZJ, LW and ZC wrote the main manuscript text. YC, YG, XF, SC, HY, WW, ZZ, MD, XZ, JL, XF and YM analyzed and interpreted the data. All authors reviewed the manuscript. All authors read and approved the final manuscript.

\section{Authors' information \\ Corresponding author: Zhe Jin, Department of Pathology, The Shenzhen University School of Medicine, 3688 Nanhai Ave, Rm 703, Nanshan, Shenzhen, Guangdong, People's Republic of China 518060; Phone: 086-0755-86671904; Fax: 086-0755-86671906; email address: zhejin1995@yahoo.com Co-Correspondence: Stephen J. Meltzer, Division of Gastroenterology, Department of Medicine, Johns Hopkins University School of Medicine. 1503 E. Jefferson Street, Rm. 112, Baltimore, MD, USA 21231; Phone: 01-410-502-6071; Fax: 01-410-502-1329; email address: smeltzer@jhmi.edu}

\section{Acknowledgements}

This study supported by National Nature Science Foundation of China grant No. 81172282, the Shenzhen Peacock Plan KQCX20130621101141669, the Planned Science and Technology Project of Shenzhen No. GJHS20120621142654087, the Key Laboratory Project of Shenzhen No. ZDSY20130329101130496, Natural Science Foundation of SZU grants 201108 and T201202 to Z Jin; NIH grant DK087454to SJ Meltzer; National Nature Science Foundation of China grant 81171921 and the Science and Technology Bureau of ShenZhen City grant JC201006010727A, JCYJ20120613165853326 and GJHS20120621154321244 to L Wang.

\section{Author details}

'Department of Pathology, The Shenzhen University School of Medicine, 3688 Nanhai Ave, Rm 703, Nanshan, Shenzhen 518060, Guangdong, People's Republic of China. 'Division of Gastroenterology, Department of Medicine, The Johns Hopkins University School of Medicine and Sidney Kimmel Comprehensive Cancer Center, Baltimore, MD, USA. ${ }^{3}$ Shenzhen Key Laboratory of Micromolecule Innovatal Drugs, The Shenzhen University School of Medicine, Shenzhen, Guangdong, People's Republic of China. "Shenzhen Key Laboratory of translational Medicine of Tumor, the Shenzhen University School of Medicine, Shenzhen, Guangdong, People's Republic of China. ${ }^{5}$ Laboratory of Chemical Genomics, School of Chemical Biology and Biotechnology, Peking University Shenzhen Graduate School, Shenzhen, Guangdong, People's Republic of China. 'Nanshan Hospital, Guangdong Medical College, Shenzhen, People's Republic of China.

Received: 22 October 2013 Accepted: 14 May 2014

Published: 20 May 2014

\section{References}

1. Jemal A, Bray F, Center MM, Ferlay J, Ward E, Forman D: Global cancer statistics. CA Cancer J Clin 2011, 61:69-90.

2. Zhang XM, Guo MZ: The value of epigenetic markers in esophageal cancer. Front Med China 2010, 4:378-384.

3. Enzinger PC, Mayer RJ: Esophageal cancer. N Engl J Med 2003, 349:2241-2252.

4. Kleinberg L, Gibson MK, Forastiere AA: Chemoradiotherapy for localized esophageal cancer: regimen selection and molecular mechanisms of radiosensitization. Nat Clin Pract Oncol 2007, 4:282-294.

5. Williams TM, Lisanti MP: The Caveolin genes: from cell biology to medicine. Ann Med 2004, 36:584-595.

6. Parton RG, Simons K: The multiple faces of caveolae. Nat Rev Mol Cell Biol 2007, 8:185-194.

7. Razani B, Lisanti MP: Caveolin-deficient mice: insights into caveolar function human disease. J Clin Invest 2001, 108:1553-1561

8. Bai L, Deng X, Li Q, Wang M, An W, Deli A, Gao Z, Xie Y, Dai Y, Cong YS: Down-regulation of the cavin family proteins in breast cancer. J Cell Biochem 2012, 113:322-328.

9. Ferraldeschi R, Latif A, Clarke RB, Spence K, Ashton G, O'Sullivan J, Evans DG, Howell A, Newman WG: Lack of caveolin-1 (P132L) somatic mutations in breast cancer. Breast Cancer Res Treat 2012, 132:1185-1186.

10. Patani N, Martin LA, Reis-Filho JS, Dowsett M: The role of caveolin-1 in human breast cancer. Breast Cancer Res Treat 2012, 131:1-15.
11. Bachmann N, Haeusler J, Luedeke M, Kuefer R, Perner S, Assum G, Paiss T, Hoegel J, Vogel W, Maier C: Expression changes of CAV1 and EZH2, located on 7q31 approximately q36, are rarely related to genomic alterations in primary prostate carcinoma. Cancer Genet Cytogenet 2008, 182:103-110.

12. Han SE, Park KH, Lee G, Huh YJ, Min BM: Mutation and aberrant expression of Caveolin-1 in human oral squamous cell carcinomas and oral cancer cell lines. Int J Oncol 2004, 24:435-440.

13. Kopantzev EP, Monastyrskaya GS, Vinogradova TV, Zinovyeva MV, Kostina MB, Filyukova OB, Tonevitsky AG, Sukhikh GT, Sverdlov ED: Differences in gene expression levels between early and later stages of human lung development are opposite to those between normal lung tissue and non-small lung cell carcinoma. Lung Cancer 2008, 62:23-34.

14. Prade E, Tobiasch M, Hitkova I, Schaffer I, Lian F, Xing X, Tanzer M, Rauser S, Walch A, Feith M, Post S, Röcken C, Schmid RM, Ebert MP, Burgermeister E: Bile acids down-regulate caveolin-1 in esophageal epithelial cells through sterol responsive element-binding protein. Mol Endocrinol 2012, 26:819-832.

15. Wang JS, Guo M, Montgomery EA, Thompson RE, Cosby H, Hicks L, Wang S, Herman JG, Canto MI: DNA promoter hypermethylation of p16 and APC predicts neoplastic progression in Barrett's esophagus. Am J Gastroenterol 2009, 104:2153-2160.

16. Agarwal $R$, Jin Z, Yang J, Mori Y, Song JH, Kumar S, Sato M, Cheng Y, Olaru AV, Abraham JM, Verma A, Meltzer SJ: Epigenomic program of Barrett's-associated neoplastic progression reveals possible involvement of insulin signaling pathways. Endocr Relat Cancer 2012, 19:L5-L9.

17. Jin Z, Cheng Y, Gu W, Zheng Y, Sato F, Mori Y, Olaru AV, Paun BC, Yang J, Kan T, Ito T, Hamilton JP, Selaru FM, Agarwal R, David S, Abraham JM, Wolfsen HC, Wallace MB, Shaheen NJ, Washington K, Wang J, Canto MI, Bhattacharyya A, Nelson MA, Wagner PD, Romero Y, Wang KK, Feng Z, Sampliner RE, Meltzer SJ: A multicenter, double-blinded validation study of methylation biomarkers for progression prediction in Barrett's esophagus. Cancer Res 2009, 69:4112-4115.

18. Jin Z, Mori Y, Hamilton JP, Olaru A, Sato F, Yang J, Ito T, Kan T, Agarwal R, Meltzer SJ: Hypermethylation of the somatostatin promoter is a common, early event in human esophageal carcinogenesis. Cancer 2008, 112:43-49.

19. Jin Z, Hamilton JP, Yang J, Mori Y, Olaru A, Sato F, Ito T, Kan T, Cheng Y, Paun B, David S, Beer DG, Agarwal R, Abraham JM, Meltzer SJ: Hypermethylation of the AKAP12 promoter is a biomarker of Barrett's-associated esophageal neoplastic progression. Cancer Epidemiol Biomarkers Prev 2008, 17:111-117.

20. Jin Z, Cheng Y, Olaru A, Kan T, Yang J, Paun B, Ito T, Hamilton JP, David S, Agarwal R, Selaru FM, Sato F, Abraham JM, Beer DG, Mori Y, Shimada Y, Meltzer SJ: Promoter hypermethylation of $\mathrm{CDH} 13$ is a common, early event in human esophageal adenocarcinogenesis and correlates with clinical risk factors. Int J Cancer 2008, 123:2331-2336.

21. Jin Z, Olaru A, Yang J, Sato F, Cheng Y, Kan T, Mori Y, Mantzur C, Paun B, Hamilton JP, Ito T, Wang S, David S, Agarwal R, Beer DG, Abraham JM, Meltzer SJ: Hypermethylation of tachykinin-1 is a potential biomarker in human esophageal cancer. Clin Cancer Res 2007, 13:6293-6300.

22. Clement G, Braunschweig R, Pasquier N, Bosman FT, Benhattar J: Methylation of APC, TIMP3, and TERT: a new predictive marker to distinguish Barrett's oesophagus patients at risk for malignant transformation. J Pathol 2006 208:100-107.

23. Tischoff I, Hengge UR, Vieth M, Ell C, Stolte M, Weber A, Schmidt WE, Tannapfel A: Methylation of SOCS-3 and SOCS-1 in the carcinogenesis of Barrett's adenocarcinoma. Gut 2007, 56:1047-1053.

24. Chan TF, Su TH, Yeh KT, Chang JY, Lin TH, Chen JC, Yuang SS, Chang JG: Mutational, epigenetic and expressional analyses of caveolin-1 gene in cervical cancers. Int J Oncol 2003, 23:599-604.

25. Chen ST, Lin SY, Yeh KT, Kuo SJ, Chan WL, Chu YP, Chang JG: Mutational, epigenetic and expressional analyses of caveolin-1 gene in breast cancers. Int J Mol Med 2004, 14:577-582.

26. Lin SY, Yeh KT, Chen WT, Chen HC, Chen ST, Chang JG: Promoter CpG methylation of caveolin-1 in sporadic colorectal cancer. Anticancer Res 2004, 24:1645-1650.

27. Mori Y, Cai K, Cheng Y, Wang S, Paun B, Hamilton JP, Jin Z, Sato F, Berki AT, Kan T, Ito T, Mantzur C, Abraham JM, Meltzer SJ: A genome-wide search identifies epigenetic silencing of somatostatin, tachykinin-1, and 5 other genes in colon cancer. Gastroenterology 2006, 131:797-808.

28. Hanley JA, McNeil BJ: The meaning and use of the area under a receiver operating characteristic (ROC) curve. Radiology 1982, 143:29-36. 
29. Chen RS, Song YM, Zhou ZY, Tong T, Li Y, Fu M, Guo XL, Dong LJ, He X, Qiao HX, Zhan QM, Li W: Disruption of XCT inhibits cancer cell metastasis via the caveolin-1/beta-catenin pathway. Oncogene 2009, 28:599-609.

30. Song Y, Xue L, Du S, Sun M, Hu J, Hao L, Gong L, Yeh D, Xiong H, Shao S: Caveolin-1 knockdown is associated with the metastasis and proliferation of human lung cancer cell line NCl-H460. Biomed Pharmacother 2012, 66:439-447.

31. Trimmer C, Sotgia F, Lisanti MP, Capozza F: Cav1 inhibits benign skin tumor development in a two-stage carcinogenesis model by suppressing epidermal proliferation. Am J Trans/ Res 2013, 5:80-91.

32. Trimmer C, Bonuccelli G, Katiyar S, Sotgia F, Pestell RG, Lisanti MP, Capozza F: Cav1 suppresses tumor growth and metastasis in a murine model of cutaneous SCC through modulation of MAPK/AP-1 activation. Am J Pathol 2013, 182:992-1004.

33. Engelman JA, Zhang $X L$, Lisanti MP: Sequence and detailed organization of the human caveolin-1 and -2 genes located near the D7S522 locus (7q31.1). Methylation of a CpG island in the 5' promoter region of the caveolin-1 gene in human breast cancer cell lines. FEBS Lett 1999, 448:221-230.

34. Jankowski JA, Harrison RF, Perry I, Balkwill F, Tselepis C: Barrett's metaplasia. Lancet 2000, 356:2079-2085.

35. Tannapfel A: Molecular findings in Barrett's epithelium. Dig Dis 2004, 22:126-133.

36. Jankowski JA, Wright NA, Meltzer SJ, Triadafilopoulos G, Geboes K, Casson AG, Kerr D, Young LS: Molecular evolution of the metaplasia-dysplasiaadenocarcinoma sequence in the esophagus. Am J Pathol 1999, 154:965-973.

37. Kuester D, Dar AA, Moskaluk CC, Krueger S, Meyer F, Hartig R, Stolte M, Malfertheiner P, Lippert H, Roessner A, El-Rifai W, Schneider-Stock R: Early involvement of death-associated protein kinase promoter hypermethylation in the carcinogenesis of Barrett's esophageal adenocarcinoma and its association with clinical progression. Neoplasia 2007, 9:236-245.

38. Kuester D, El-Rifai W, Peng D, Ruemmele P, Kroeckel I, Peters B, Moskaluk CA, Stolte M, Monkemuller K, Meyer F, Schulz HU, Hartmann A, Roessner A, Schneider-Stock R: Silencing of MGMT expression by promoter hypermethylation in the metaplasia-dysplasia-carcinoma sequence of Barrett's esophagus. Cancer Lett 2009, 275:117-126.

39. Williams TM, Lisanti MP: Caveolin-1 in oncogenic transformation, cancer, and metastasis. Am J Physiol Cell Physiol 2005, 288:C494-C506.

40. Navarro A, Anand-Apte B, Parat MO: A role for caveolae in cell migration. Faseb J 2004, 18:1801-1811.

41. Goetz JG, Lajoie P, Wiseman SM, Nabi IR: Caveolin-1 in tumor progression: the good, the bad and the ugly. Cancer Metastasis Rev 2008, 27:715-735.

42. Burgermeister E, Liscovitch M, Rocken C, Schmid RM, Ebert MP: Caveats of caveolin-1 in cancer progression. Cancer Lett 2008, 268:187-201.

43. Kato K, Hida Y, Miyamoto M, Hashida H, Shinohara T, Itoh T, Okushiba S, Kondo S, Katoh H: Overexpression of caveolin-1 in esophageal squamous cell carcinoma correlates with lymph node metastasis and pathologic stage. Cancer 2002, 94:929-933.

44. Ando T, Ishiguro H, Kimura M, Mitsui A, Mori Y, Sugito N, Tomoda K, Mori R, Harada K, Katada T, Ogawa R, Fujii Y, Kuwabara Y: The overexpression of caveolin-1 and caveolin-2 correlates with a poor prognosis and tumor progression in esophageal squamous cell carcinoma. Oncol Rep 2007, 18:601-609.

45. Das M, Das S, Lekli I, Das DK: Caveolin induces cardioprotection through epigenetic regulation. J Cell Mol Med 2012, 16:888-895.

46. Tsuji Y, Nakagawa T, Hatanaka M, Takeuchi T, Matsumoto E, Takenaka H, Shimizu A: Quantification of caveolin isoforms using quantitative real-time RT-PCR, and analysis of promoter $\mathrm{CpG}$ methylation of caveolin-1alpha in human T cell leukemia cell lines. Int J Mol Med 2006, 18:489-495.

47. Lemaire M, Momparler LF, Bernstein ML, Marquez VE, Momparler RL: Enhancement of antineoplastic action of 5-aza-2'-deoxycytidine by zebularine on L1210 leukemia. Anticancer Drugs 2005, 16:301-308.

48. Momparler RL: Epigenetic therapy of cancer with 5-aza-2'-deoxycytidine (decitabine). Semin Oncol 2005, 32:443-451.

49. Mirza S, Sharma G, Pandya P, Ralhan R: Demethylating agent 5-aza-2-deoxycytidine enhances susceptibility of breast cancer cells to anticancer agents. Mol Cell Biochem 2010, 342:101-109.

\section{Submit your next manuscript to BioMed Central and take full advantage of:}

- Convenient online submission

- Thorough peer review

- No space constraints or color figure charges

- Immediate publication on acceptance

- Inclusion in PubMed, CAS, Scopus and Google Scholar

- Research which is freely available for redistribution 